\title{
Prevalence of Risk Factors for Non-Communicable Diseases in Mazar-e-Sharif city using WHO STEP-Wise Approach
}

\author{
Khwaja Mir Islam Saeed (MD, MSc) ${ }^{1},{ }^{2}$ Mohammad Hafez Rasooly (MD, MSc) \\ ${ }^{1}$ Head of Grant and Service Contract Management Unit (GCMU), Ministry of Public Health (MoPH), Kabul- \\ Afghanistan, Tel: 0093700290955, ${ }^{2}$ Influenza Surveillance Officer, Surveillance Department, MoPH
}

\begin{abstract}
Background: Afghanistan is suffering from double burden of diseases including communicable and noncommunicable. The aim of this study was determine the risk factors for NCDs among adult's population in Mazar-e-Sharif city, Afghanistan.

Methods and Materials: A provincial cross-sectional study was conducted from April to May 2015 on the prevalence of NCD risk factors using the WHO STEPS adapted instrument. The study enrolled a random sample of 1249 adults of age group of 25-70 years. Data were collected using a structured questionnaire. Fasting venous blood sample was collected to assess the lipid profile and fasting blood sugar. Anthropometric measurements of the participants were also taken. Data was analyzed using SPSS version 20.

Results: Out of all (1231) respondents $664(53.9 \%)$ were females and $567(46.1 \%)$ males with a mean age of $40.5 \pm 13.2$ years. More than half $(59.3 \%)$ were illiterates and $(83.7 \%)$ were married and $72 \%$ had income of less than 10000 AFN. 9.9\% were smokers and $(8.3 \%)$ were mouth snuff users. Seventy nine percent of respondents ate fruits and $60 \%$ took vegetables 3 days or less per week. Almost 12\% practiced vigorous physical activity and $21.8 \%$ of subjects reported doing moderate physical activity. Almost half (48.5) of subjects were overweight or obese. 30.9\% had high blood pressure and 9.2\% percent recorded diabetic. Level of high cholesterol was 33.2\%, high triglycerides was $20.4 \%$. Furthermore high level of low density lipoprotein (LDL) was 55\% and high level of high density lipoprotein (HDL) was 36.9\%. The mean level of triglyceride, total cholesterol, HDL and LDL were $161.7 \mathrm{mg} / \mathrm{dL}, 179.2 \mathrm{mg} / \mathrm{dL}, 49.4 \mathrm{mg} / \mathrm{dL}$ and $113.4 \mathrm{mg} / \mathrm{dL}$ were respectively.

Conclusions: The findings of study revealed a high burden of risk factors for NCDs in the study population, showing the country is experiencing both communicable and noncommunicable at the same time. It is recommended and emphasized on focusing of interventions to prevent and control the noncommunicable diseases.
\end{abstract}

Keywords: -Non-communicable diseases, risk factors, prevalence, WHO step approach, Balkh

\section{INTRODUCTION}

Non-communicable Diseases (NCDs) are chronic medical conditions with long duration and slow progression. Global attention is given to NCDs and new health goal is to reduce mortality from NCDs by $25 \%$ by 2025: the 25 by 25 goal [1]. NCDs cause more deaths than all other causes combined and such deaths are projected to increase from 38 million in 2012 to 52 million by 2030 [2]. Of the total deaths attributed to NCDs globally, nearly $80 \%$ occur in low-and middle-income countries [3]. Furthermore, NCDs kill at a younger age in developing countries, including those of the Eastern Mediterranean Region (EMR). In some EMR countries up to $50 \%$ of those who die from such diseases die before the age of 60 years compared with less than $10 \%$ in Western Europe [4]. The global economic burden of NCDs is huge [5] and disproportionately affects poorer individuals in low-income countries [6].

In Afghanistan, as in other countries of the EMR, most of the costs of health care, particularly for NCDs, are paid directly by patients out-of-pocket, and therefore can be a significant burden on household budgets [7]. People are dying in younger age in Afghanistan due to NCDs. An analysis shows the proportion of men dying under the age of 60 from NCDs was as high as $63 \%$ and among women under 60 years, the highest proportion of premature deaths was $51 \%$ in Afghanistan[8]. According to World Health Organization (WHO) estimates the age-standardized death rates due to all NCDs were 1285 per 100000 population for males and 952 per 100000 for females [9]. Furthermore, the Afghanistan mortality survey 2010 revealed that $33.3 \%$ of all deaths in Afghanistan were attributed to NCDs, with cardiovascular diseases, malignant neoplasm, diabetes, respiratory diseases and digestive diseases accounting for $14.0 \%, 7.3 \%, 3.7 \%, 1.9 \%$ and $1.8 \%$ of total NCDs deaths respectively [10]. Based on WHO estimates, in 2000 there were 468000 people with diabetes in Afghanistan. This number is expected to rise to 1403000 in 2030, representing nearly a 3-fold increase compared with 2000 [11]. In a study among men aged 15 years and older in Kabul city the prevalence of smoking was 35\% [12], while in a study to identify the prevalence and risk factors of NCDs among the older adult population (aged $\geq 40$ years) in Kabul city in 2012, the prevalence of diabetes mellitus was reported to be 
$13.3 \%$, obesity was $31.2 \%$ and hypertension was $46.2 \%$ [13]. A recent study on NCDs in Jalalabad city an eastern big city of the country showed that the prevalence of overweight/obesity, diabetes and hypertension were $57.4 \%, 11.4 \%$ and $24.4 \%$ respectively. Among respondents, $8.0 \%$ reported being current cigarette smokers and $13.7 \%$ used mouth snuff; $69.8 \%$ and $19.6 \%$ had $<3$ servings of fruits and of vegetables respectively in a week; and $33.5 \%$ and $57.8 \%$ reported vigorous and moderate physical activity respectively [14]. Afghanistan being a conflict affected country and limited capacity could be vulnerable to NCDs due to high level of psychological stress, rapid urbanization and aggressive food marketing response. Despite of government the Afghanistan's donor partners have not prioritized preventive or curative services for noncommunicable diseases in their programs [15]. It is believed that a large proportion of NCDs can be prevented by reducing the 4 main risk factors: tobacco use, physical inactivity, unhealthy diet and the harmful use of alcohol [5]. In Afghanistan, due to competing priorities and many years of conflict, little information is available about the prevalence and risk factors for NCDs. However, facts and figures from neighbouring countries such as Pakistan and the Islamic Republic of Iran give cause for concern [16-20]. Given that the risk of mortality due to NCDs has overtaken that due to communicable diseases in Afghanistan [10], there is insufficient evidence about the risk factors associated with NCDs in the country. A previous study of risk factors in Kabul city could not be generalizable to all Afghanistan with its variety of different geography, risk behaviours and cultural backgrounds. Therefore, to fill this knowledge gap the present study aimed to identify the prevalence of risk factors for chronic NCDs in the urban population of Balkh province.

\section{METHODS AND MATERIALS}

We conducted a provincial cross sectional survey in Mazar-e-Sharif a northern urban city of Afghanistan adapting and using the WHO STEP-wise tool [21]. All permanent household members aged more than 25 years, including men and women who were residents of the cities during the study period and gave consent to participate were included in the study. Temporary residents (resident $<6$ months) and those living in institutionalized settings or insecure areas were excluded. Due to the unavailability of previous estimates of risk factor prevalence in this city we assumed the highest prevalence or sample size calculation (50\%), 95\% confidence interval (CI) and margin of error of 5\%. From this we estimated 385 subjects to be included in the survey. Taking into consideration the proportion of other risk factors in similar settings, the number of subjects was increased to 600. Finally, after taking into account the design effect $(\mathrm{DE}=2)$ of cluster sampling the final sample size was increased to $(2 \times 600)=1200$ for the city, which was reasonable for achieving the study objectives with limited resources and funding support.

\section{Sampling Techniques and Strategy:}

Initially we obtained the list of all existed city districts from Mazar-e-Sharif municipality website. It includes the name, population size, number of households and its boundaries. Using the multistage cluster strategy at onset from this list we conventionally selected five districts using random number of excel sheet. In the second stage from each selected district we randomly selected the five areas (called Guzar). Later the overall sample of 1200 household distributed among these selected area according to the proportion to the size of household number in each districts/ areas. Later on the number of households in each area divided by the sample size assigned for each areas, it enabled us to select household systematically. Within household the adults of more than 25 years counted and randomly one of them selected and interviewed.

\section{Data collection:}

Training and field test was conducted ahead of time and questionnaire were adjusted before actual data collection (April-May 2015). Anthropometric measurement and blood sample collection practices sufficiently during field test. A household was defined as a group of people who share the same food pot (not the same roof). In each household the interviewer enumerated all persons who were eligible for our study based on the inclusion criteria. In households with more than one eligible person, we used a lottery system to select the respondent for this survey. In cases of refusal, which was less than $5 \%$, the interviewer approached the next alternate household. Various group of targeted data including demographic, behavioural and clinical variables were collected in Mazar-e-Sharif city from April to May 2015 using the WHO STEP-wise instrument. Anthropometric measurements (height and weight) were used to calculate body mass index (BMI). A BMI of $\geq 30 \mathrm{~kg} / \mathrm{m} 2$ was considered as obese, $25-30 \mathrm{~kg} / \mathrm{m} 2$ as overweight and $18.5-25 \mathrm{~kg} / \mathrm{m} 2$ as normal weight [22]. A waist circumference of $94 \mathrm{~cm}$ for men and $80 \mathrm{~cm}$ for women was considered as central obesity (23]. Systolic blood pressure $140 \mathrm{mmHg}$ and diastolic pressure $90 \mathrm{mmHg}$ were considered as hypertensive [24]. A fasting blood sugar of $\geq 126 \mathrm{mg} / \mathrm{dL}$ was considered as diabetes mellitus [25].

Following the interview blood samples were collected the next morning after the respondent were fasted for 1012 hours. Blood samples were transported in cool boxes $\left(2-8^{\circ} \mathrm{C}\right)$ from field to provincial public health office on the day of sample collection. After processing and separation the samples were shipped to Central Public 
Health Laboratory (CPHL) in Kabul in consignments. Using Cry-vials the samples were coded with ID number of the questionnaire. On arrival in CPHL all serum samples were stored at $-80^{\circ} \mathrm{C}$ until biochemical test conducted. Altogether 1231 blood samples were tested for biochemical measurement of triglyceride, cholesterol, and glucose, except 18 samples which were poor and discarded.

\section{Data Analysis:}

Data were entered in Epi-info, version 7, and cleaned data was analysed using SPSS, version 20. Descriptive analysis was done in order to explain and describe the proportion of NCDs and factors.

\section{RESULTS}

A total of 1249 individuals were interviewed and approached, however the final analysis were performed on 1231 records and 18 were discorded due to not matching the requirements. The proportion of males and females was $46.1 \%$ and $53.9 \%$ respectively with a mean age of $40.5 \pm 13.2$ years; two third $(68.5 \%)$ of the study participants were aged less than 45 years. More than half of the respondents $(59.3 \%)$ were illiterates; and $72 \%$ of the participants had income of less than 10000 AFN (USD150). Majority of respondents (83.7\%) were married and more than $85.5 \%$ of women were housewives (Table 1).

Table 2 represents the prevalence of various risk factors for NCD in Mazar-e-Sharif. Almost 10\% were smokers as a whole while it was $14.8 \%$ in males. At least 20 years was duration of smoking for $83 \%$ of the participants who were smokers. Furthermore $(8.3 \%)$ were mouth snuff users with differentiation of $3.5 \%$ among women. Eighty percent of respondents ate fruits 3 days or less per week while it was increased to half with respect to vegetables. Half of respondents reported to use liquid oil for cooking in their kitchen. Almost $12 \%$ of the respondents practiced vigorous physical activity and $28.2 \%$ of subjects reported doing moderate physical activity. Almost $37 \%$ of respondents reported to walk or use bicycle for 10 minutes per day. Two third (65\%) of respondents recorded a reclining of three hours or more per day.

Table 3 represents that prevalence of pathophysiological risk factors of study participants. Close to half (48.5\%) of study respondents were recorded to be as overweight or obese. Almost more than half (58.9\%) were suffering from central obesity as a whole while it was more prevalent among women (75\%).

Only $42 \%$ and $27.1 \%$ of the respondents had low or normal blood pressure respectively while $30.9 \%$ had high blood pressure predominantly higher among female (36\%). Almost 9.2\% percent recorded as diabetic, of them the prevalence of diabetes $10.4 \%$ were for females and $8.1 \%$ for males. Level of total cholesterol with cut off $190 \mathrm{mg} / \mathrm{dL}$ and level of triglyceride with cut off $150 \mathrm{mg} / \mathrm{dL}$ were high in proportion of $33.2 \%$ and $20.4 \%$ respectively. Furthermore high level of low density lipoprotein (LDL) with cut of $100 \mathrm{mg} / \mathrm{dL}$ were $55 \%$ and low level of high density lipoprotein (HDL) with cut of less than 40 were both $63.1 \%$. The mean level of triglyceride, total cholesterol, HDL and LDL were $161.7 \mathrm{mg} / \mathrm{dL}, 179.2 \mathrm{mg} / \mathrm{dL}, 49.4 \mathrm{mg} / \mathrm{dL}$ and $113.4 \mathrm{mg} / \mathrm{dL}$ were respectively.

\section{DISCUSSION}

The main priority for health system to response in last decade was and still is management of maternal and child, health, communicable diseases, malnutrition, vaccination, mental health and disability [26]. Accordingly, negligible efforts have been carried out to reduce NCD and their risk factors, except inclusion in national health policy recently [27]. This study was carried out to assess the common risk factors [28-29] for NCD in urban population of Balkh province. It includes almost equal proportion of males and females. Average age of adult population was almost 40 years of which majority were younger than 45 years. This could explain and match the life expectancy of 62 years published in Afghanistan [10]. Higher level of illiteracy rates and lower level of monthly income shows a tremendous situation in the country. Lower status of women could be understood by their involvement within homes close to 85 percent. Using tobacco were explained by smoking and using mouth snuff. Approximately one tenth of adults in Mazar-e-Sharif city were smoking while it raised to $15 \%$ for males. It is comparable with other study in Jalalabad city in which the prevalence of smoking among adult population was $8 \%$ and prevalence of using mouth snuff was $13.7 \%$ [30] In addition using snuff by mouth is bad habit in the city (8\%) similar to other setting in Afghanistan. Eating fruits and vegetables were a good habit of study participants. The probability of eating fruits seems less as compare to vegetables which could be due to high cost of fruit and low cost of vegetables. However this is supported by study in Jalalabad city [30] which is needed to be encouraged. Physical activity was common among adults in Mazar-e-Sharif city by nature of their work. For instance, $12 \%$ were busy by doing vigorous physical activity while one fifth were involved in moderate physical activity. Although this proportion is a bit lower than Jalalabad city [30], however that is a good point to be focused.

As reflected in other studies in the country $[13,30]$ more than half of the adult's population in Mazar-e-Sharif city were suffering from overweight and obesity. Our findings on obesity are consistent with global and largescale studies in other parts of the world [31-33]. Moreover, cultural norms in Afghanistan mean that being 
overweight and obese is perceived as healthy and people are generally not interested in losing weight. However being obese is a big problem and it should be given sufficient attention in the country. Furthermore results of this study shows almost one third of adult population is suffering from high blood pressure and one tenth are suffering from diabetes which both are significant findings. In an earlier study in Kabul city the prevalence of hypertension was $46.0 \%$ and of diabetes was $13.7 \%$, rates which are higher than in current study perhaps due to cultural differences and to the older age groups sampled in that study [13] or the reason was the age of the participant of more than 40 years. In addition the study in Jalalabad [30] showed that $28.4 \%$ were suffering from high blood pressure and $11.4 \%$ were suffering from diabetes which looks consistent with these findings. In addition, a systematic study (1996-2004) in the Islamic Republic of Iran, which is a neighbouring county to Afghanistan estimated that the overall prevalence of hypertension and diabetes in the population aged 30-55 and $>55$ years were around 23\% and 50\% respectively [33]. In Punjab province in Pakistan, another neighbouring country, the prevalence of diabetes was reported to be $12.1 \%$ in males and $9.8 \%$ in females which the similar sex distribution reported by this study [17].As noted the prevalence of hypertension was relatively higher among female than male participants. This is could be due the higher rate of central obesity among female than males. The prevalence of high blood pressure was consistent with overall prevalence of hypertension in Karachi, Pakistan which was reported at $26 \%$. Therefore there is a need for health education campaigns in the country to be focused on overall risk factors. Men are at greater risk of non-communicable disease than women, which is not a modifiable risk factor and could be due to genetic differences. Sex differences in risk factors were also demonstrated in Karachi in Pakistan [31].

According to our findings the one tenth of subject were smokers and $8 \%$ were using mouth snuff which is much higher in men as compare to women, if analysed separately. The sex differences in smoking patterns are similar to other studies [35-36]. Using of mouth snuff, smoking, physical activity are much lower in the country due to cultural background. It is an area for focus and action. As a common sense NCDs and their risk factors occur as a combined syndrome in the adult population. Meaning that an obese person who is smoking and affected by diabetes has a greater chance of being affected by NCDs. The more risk factors the greater the probability of NCDs among the adult population. This study hypothesized that the population in the urban setting of this province were entering a critical state of NCDs, while little attention was being given to the issue. Interventions are needed to target a group of risk factors rather than just one or two factors. As a whole the proportion of obesity and overweight, central obesity, hypertension and diabetes were higher among female as compare to males while the level of exercise were low in females as compare to males. This is one of the major and unique findings of this study which requires serious attention and policy makers. There is need to move beyond inclusion of NCD in national policy and develop and implement focused interventions.

Financial constraint has always been a limitation which prevented listing of the households before the survey so we approached the community and selected the households directly. Secondly, due to the available free measurement of blood pressure and lab tests, there might be more hypertensive and diabetic patient participated in the study. Therefore, it may lead to slight overestimation of the findings. Furthermore, the poor security situation which forced us to exclude rural areas from our study. Regardless of these limitations this study has provided some useful baseline information for policy development and the design of interventions. The study could promote WHO office to support MoPH to design and implement a nationwide survey using the WHO STEP-wise approach in order to obtain a more complete picture of the risk of NCDs in the country. NCD services with screening systems could be an integrated to primary health care.

\section{ACKNOWLEDGEMENTS}

We would like to thank Surveillance Department at the Ministry of Public Health as well as provinces and the WHO Kabul office for supporting the study.

\section{REFERENCES}

[1] Prevention and control of non-communicable diseases. Outcome of the High-Level Meeting of the General Assembly on the Prevention and Control of Non-communicable Diseases and the First Global Conference on Health Lifestyles and Non-communicable Disease Control. Sixty-fifth World Health Assembly, 20 April 2012. Provisional agenda item 13.1 (A65/6). Geneva: World Health Organization; 2012.

[2] World Health Organization. Global status report on noncommunicable diseases 2014. Available on the WHO website (www.who.int)

[3] The global burden of disease: 2004 update. Geneva: World Health Organization; 2008 http://www.who.int/healthinfo/global_burden_disease/GBD_report_2004update_full.pdf?ua=1, accessed 29 July 2015). 
[4] The Political Declaration of the United Nations General Assembly on the Prevention and Control of NonCommunicable Diseases: Commitments of Member States and the way forward .Technical Discussion paper. Fifty-ninth session of the Regional Committee for the Eastern Mediterranean, August2012. $\begin{array}{llll}\text { Provisional } & \text { agenda } & \text { item } & \text { (a) }\end{array}$ (http://applications.emro.who.int/docs/RC_technical_papers_2012_3_14578_EN.pdf, accessed 29 July 2015).

[5] Global status report on noncommunicable diseases 2010.Geneva: World Health Organization; 2011 (http://www.who.int/nmh/publications/ncd_report_full_en.pdf, accessed 29 July 2015).

[6] Kankeu HT, Saksena P, Xu K, Evans DB. The financial burden from noncommunicable diseases in lowand middle-income countries: a literature review. Health Res Policy Syst. 2013 Aug 16;11:31

[7] Health systems strengthening in countries of the Eastern Mediterranean Region: challenges, priorities and options for future action. Technical discussion paper. Fifty-ninth session of the Regional Committee for the Eastern $\quad$ Mediterranean, October2012 (EM/RC59/Tech.Disc.1) (http://applications.emro.who.int/docs/RC_technical_papers_2012_Tech_Disc_1_14613_EN.pdf, accessed 20 December 2013).

[8] John Zarocostas. Deaths from non-communicable diseases are highest in Afghanistan, lowest in Sweden. BMJ 2011;343:d5876

[9] Afghanistan. In: Noncommunicable diseases: country profiles 2011. Geneva: World Health Organization; 2011 (http://www.who.int/nmh/publications/ncd_profiles_report.pdf) accessed 29 July 2015.

[10] Afghanistan mortality survey 2010. Calverton (MD): Afghan Public Health Institute, Ministry of Public Health, Central Statistics Organization (Afghanistan), ICF Macro, Indian Institute of Health Management Research and World Health Organization Regional Office for the Eastern Mediterranean; 2011 (http://dhsprogram.com/pubs/pdf/FR248/FR248.pdf, accessed 29 July 2015).

[11] World Health Organization, Diabetes programme Country and regional data on diabetes Prevalence of diabetes in the WHO Eastern Mediterranean Rion. (http://www.who.int/diabetes/facts/world_figures/en/index2.html. accessed 29 July 2015)

[12] Mohmand. K.A, Sharifi K, Bahram A.A. Smoking prevalence survey in Kabul City. Kabul. Social and Health Development Program.2010 (in press).

[13] Saeed KMI. Prevalence of risk factors for NCDs in the adult population of urban areas in Kabul city, Afghanistan. Cent Asian J Glob Health.2013;2(2): 10.5195/cajgh.2013.69

[14] Saeed KMI, Rasooly MH, Alkozai A. Prevalence of risk factors for noncommunicable diseases in Jalalabad city, Afghanistan, evaluated using the WHO STEP-wise approach. EMHJ. 2015; 21(11)

[15] Bayard Roberts, PreetiPatelb, Martin McKeea. Noncommunicable diseases and post-conflict countries. Bull World Health Organ 2012; 90:2-2A. doi:10.2471/BLT.11.098863

[16] Esteghamati A, Meysamie A, Khalilzadeh O, Rashidi A, Haghazali M, Asgari F, et al. Third national surveillance of risk factors of NCDs (SuRFNCD-2007) in Iran: methods and results on prevalence of diabetes, hypertension, obesity, central obesity, and dyslipidemia. BMC Public Health.2009; 9:167.

[17] BastiA,Fawwad A, Hakeem R, Ahmedani MYM, Zafar M. Pakistan National Diabetes Survey: prevalence of glucose intolerance and associated factors in the Punjab province of Pakistan. Journal of Primary Care Diabetes Europe. (2010).4 (2); 79-83.

[18] Safdar S, Omair A, Faisal U, Hasan H. Prevalence of hypertension in a low income settlement of Karachi, Pakistan.J Pak Med Assoc. 2004Oct;54(10):506-9.

[19] Musaiger AO. Overweight and obesity in the Eastern Mediterranean Region: can we control it? East Mediterr Health J. 2004Nov; 10(6):789-93.

[20] Veghari G, Sedaghat M, Joshaghani H, Hoseini A, Niknezhad F, Angizeh A, et al. The prevalence of obesity and its related risk factor in the north of Iran in 2006.J Res Health Sci. 2010; 10(2):116-21.

[21] Bonita R, deCourten M, Dwyer T, Jamrozik K, Winkelmann R. Surveillance of risk factors for noncommunicable diseases: the WHO STEP-wise approach. Geneva: World Health Organization; 2002 (WHO/NMH/CCS/01.2002).

[22] Obesity: preventing and managing the global epidemic. Geneva: World Health Organization; 2000 (WHO Technical Report Series No. 894).

[23] The IDF consensus worldwide definitions of the metabolic syndrome. Brussels: International Diabetes Federation; 2006 (http://www.idf.org/webdata/docs/IDF_Meta_def_final.pdf, accessed 29 July 2015). 
[24] Whitworth JA; World Health Organization, International Society of Hypertension Writing Group. World Health Organization (WHO)/International society of Hypertension (ISH) statement on management of hypertension. J Hypertens.2003Nov; 21(11):1983-92.

[25] Diabetes. Fact sheet no. 312. Updated January 2015.Geneva: World Health Organization; 2015 (http://www.who.int/mediacentre/factsheets/fs312/en/, accessed 29 July 2015).

[26] Basic Package of Health Services, 2010. Ministry of Public Health, Kabul Afghanistan

[27] Afghanistan National Health Policy (2015-2020). Islamic Republic of Afghanistan, Ministry of Public Health

[28] Health management information system (HMIS). In: Annual Report 1394. Kabul, Afghanistan: Ministry of Public Health; 2015

[29] Disease early warning system (DEWS) surveillance. In: Annual Report. Kabul, Afghanistan: Afghan National Public Health Institute, Ministry of Public Health; 2013.

[30] Saeed KMI, Rasooly MH, Alkozai A. Prevalence of risk factors for noncommunicable diseases in Jalalabad city, Afghanistan, evaluated using the WHO STEP-wise approach. EMHJ. 2015; 21(11).

[31] Stevens GA, Singh GM, Lu Y, Danaei G, Lin JK, Finucane MM, et al.; Global Burden of Metabolic Risk Factors of Chronic Diseases Collaborating Group (Body Mass Index). National, regional, and global trends in adult overweight and obesity prevalence. Popul Health Metr. 2012; 10(1):22-2.

[32] Finucane MM, Stevens GA, Cowan MJ, Danaei G, Lin JK, Paciorek CJ, et al.; Global Burden of Metabolic Risk Factors of Chronic Diseases Collaborating Group (Body Mass Index). National, regional, and global trends in body-mass index since 1980: systematic analysis of health examination surveys and epidemiological studies with 960 country-years and 9•1 million participants. Lancet. 2011 Feb 12; 377(9765):557-67.

[33] Khuwaja AK, Kadir MM. Gender differences and clustering pattern of behavioural risk factors for chronic NCDs: community-based study from a developing country. Chronic Illn. 2010 Sep; 6(3):163-70.

[34] Haghdoost AA, Sadeghirad B, Rezazadehkermani M. Epidemiology and heterogeneity of hypertension in Iran: a systematic review. Arch Iran Med. 2008 Jul; 11(4):444-52.

[35] WHO STEPS. Chronic disease risk factor surveillance. Data book, I.R. Iran 1388 (2009) [Internet] (http://www.who.int/chp/steps/Iran_DataBook_2009.pdf?ua=1, accessed 29 July 2015).

[36] Pan B, Chen X, Wu X, Li J, Li J, Li Y, et al. Prevalence of noncommunicable diseases and their risk factors in Guangzhou, China. Prev Chronic Dis. 2014; 11:130091

\begin{tabular}{|c|c|c|c|c|c|c|c|}
\hline \multirow[t]{2}{*}{ Variables } & \multirow[t]{2}{*}{ Categories } & \multicolumn{2}{|c|}{ Female } & \multicolumn{2}{|c|}{ Male } & \multicolumn{2}{|c|}{ Total } \\
\hline & & $\mathbf{N}$ & $\%$ & $\mathbf{N}$ & $\%$ & $\mathbf{N}$ & $\%$ \\
\hline \multicolumn{8}{|l|}{ Age } \\
\hline & $25-34$ & 305 & 45.9 & 255 & 45 & 560 & 45.5 \\
\hline & $35-44$ & 175 & 26.4 & 108 & 19 & 283 & 23 \\
\hline & $45-54$ & 112 & 16.9 & 76 & 13.4 & 188 & 15.3 \\
\hline & $55+$ & 72 & 10.8 & 128 & 22.6 & 200 & 16.2 \\
\hline \multicolumn{8}{|c|}{ Level of Education } \\
\hline & Illiterate & 472 & 71 & 258 & 45.5 & 730 & 59.3 \\
\hline & Primary and unofficial & 118 & 17.8 & 152 & 26.8 & 270 & 21.9 \\
\hline & Secondary school & 37 & 5.6 & 82 & 14.5 & 119 & 9.7 \\
\hline & High school and over & 37 & 5.6 & 74 & 13.1 & 111 & 9 \\
\hline & Refused & 0 & 0 & 1 & 0.2 & 1 & 0.1 \\
\hline \multicolumn{8}{|c|}{ Job Categories } \\
\hline & Official Employees & 26 & 3.9 & 100 & 17.6 & 126 & 10.2 \\
\hline & Students & 11 & 1.7 & 25 & 4.4 & 36 & 2.9 \\
\hline & Private Business & 3 & 0.5 & 125 & 22 & 128 & 10.4 \\
\hline & Worker/Farmer & 14 & 2.1 & 176 & 31 & 190 & 15.4 \\
\hline & Jobless & 14 & 2.1 & 55 & 9.7 & 69 & 5.6 \\
\hline & Housework & 568 & 85.5 & 10 & 1.8 & 578 & 47 \\
\hline & Unable to work/DKN & 28 & 4.2 & 76 & 13.4 & 104 & 8.4 \\
\hline
\end{tabular}


Prevalence of Risk Factors for Non-Communicable Diseases in Mazar-e-Sharif city using WHO STEP-

\begin{tabular}{|l|l|l|l|l|l|l|l|}
\hline & Less than 10000 & 471 & 70.9 & 415 & 73.2 & 886 & 72 \\
\hline & More than 10000 & 135 & 20.3 & 110 & 19.4 & 245 & 19.9 \\
\hline & Refused & 58 & 8.7 & 42 & 7.4 & 100 & 8.1 \\
\hline \multicolumn{7}{|l|}{} \\
\hline Marital Status & Single & 41 & 6.2 & 80 & 14.1 & 121 & 9.8 \\
\hline & Married & 552 & 83.1 & 478 & 84.3 & 1030 & 83.7 \\
\hline & Widow/Widower & 71 & 10.7 & 8 & 1.4 & 79 & 6.4 \\
\hline & Divorced & 0 & 0 & 1 & 0.2 & 1 & 0.1 \\
\hline
\end{tabular}

Table 2: Frequency distribution of behavioral risk factors for noncommunicable diseases among the study participants, Mazar-e-Sharif city $(\mathrm{N}=1231)$

\begin{tabular}{|c|c|c|c|c|c|c|c|}
\hline \multirow[t]{2}{*}{ Variables } & \multirow[t]{2}{*}{ Categories } & \multicolumn{2}{|c|}{ Female } & \multicolumn{2}{|c|}{ Male } & \multicolumn{2}{|l|}{ Total } \\
\hline & & $\mathbf{N}$ & $\%$ & $\mathbf{N}$ & $\%$ & $\mathbf{N}$ & $\%$ \\
\hline \multicolumn{8}{|c|}{ Cigarette Smoking Status } \\
\hline & No & 626 & 94.3 & 483 & 85.2 & 1109 & 90.1 \\
\hline & Yes & 38 & 5.7 & 84 & 14.8 & 122 & 9.9 \\
\hline \multicolumn{8}{|c|}{ Duration of smoking in years (past and current smokers) } \\
\hline & $<10$ years & 22 & 48.9 & 36 & 34.3 & 58 & 38.7 \\
\hline & $10-20$ years & 20 & 44.4 & 47 & 44.8 & 67 & 44.7 \\
\hline & $\geq 20$ years & 3 & 6.7 & 22 & 21 & 25 & 16.7 \\
\hline \multicolumn{8}{|c|}{ Mouth Snuff Status } \\
\hline & No & 641 & 96.5 & 488 & 86.1 & 1129 & 91.7 \\
\hline & Yes & 23 & 3.5 & 79 & 13.9 & 102 & 8.3 \\
\hline \multicolumn{8}{|c|}{ Fruit taking ( days per week) } \\
\hline & $<3$ & 544 & 82.2 & 428 & 75.8 & 972 & 79.2 \\
\hline & $\geq 3$ & 118 & 17.8 & 137 & 24.2 & 255 & 20.8 \\
\hline \multicolumn{8}{|c|}{ Vegetables taking (days per week) } \\
\hline & $<3$ & 309 & 46.5 & 317 & 55.9 & 626 & 50.9 \\
\hline & $\geq 3$ & 355 & 53.5 & 250 & 44.1 & 605 & 49.1 \\
\hline \multicolumn{8}{|c|}{ Type of Kitchen Oil } \\
\hline & Liquid & 303 & 45.6 & 324 & 57.1 & 627 & 50.9 \\
\hline & Solid & 266 & 40.1 & 171 & 30.2 & 437 & 35.5 \\
\hline & Both & 93 & 14 & 68 & 12 & 161 & 13.1 \\
\hline & Refused & 2 & 0.3 & 4 & 0.7 & 6 & 0.5 \\
\hline \multicolumn{8}{|c|}{ Vigorous Physical Activity } \\
\hline & No & 608 & 91.6 & 470 & 82.9 & 1078 & 87.6 \\
\hline & Yes & 56 & 8.4 & 97 & 17.1 & 153 & 12.4 \\
\hline \multicolumn{8}{|c|}{ Moderate Physical Activity } \\
\hline & No & 502 & 75.6 & 382 & 67.4 & 884 & 71.8 \\
\hline & Yes & 162 & 24.4 & 185 & 32.6 & 347 & 28.2 \\
\hline \multicolumn{8}{|c|}{ Pedal or bicycle for 10 Minutes per day } \\
\hline & No & 614 & 92.5 & 156 & 27.5 & 770 & 62.6 \\
\hline & Yes & 50 & 7.5 & 411 & 72.5 & 461 & 37.4 \\
\hline \multicolumn{8}{|c|}{ Reclining/siting (hours per day) } \\
\hline & $<3$ & 194 & 29.3 & 234 & 41.3 & 428 & 35 \\
\hline & $\geq 3$ & 467 & 70.7 & 333 & 58.7 & 800 & 65 \\
\hline
\end{tabular}




\begin{tabular}{|c|c|c|c|c|c|c|c|}
\hline \multirow[t]{2}{*}{ Variables } & \multirow[t]{2}{*}{ Categories } & \multicolumn{2}{|c|}{ Female } & \multicolumn{2}{|c|}{ Male } & \multicolumn{2}{|l|}{ Total } \\
\hline & & $\mathrm{N}$ & $\%$ & $\mathrm{~N}$ & $\%$ & $\mathrm{~N}$ & $\%$ \\
\hline \multicolumn{8}{|c|}{ Basic Mass index (in kg/m square) } \\
\hline & Underweight $^{1}$ & 46 & 6.9 & 28 & 4.9 & 74 & 6 \\
\hline & Normal weight $^{2}$ & 292 & 44 & 257 & 45.3 & 549 & 44.6 \\
\hline & Overweight $^{3}$ & 190 & 28.6 & 228 & 40.2 & 418 & 34 \\
\hline & Obesity $\mathrm{I}^{4}$ & 94 & 14.2 & 46 & 8.1 & 140 & 11.4 \\
\hline & Obesity II $^{5}$ & 28 & 4.2 & 6 & 1.1 & 34 & 2.8 \\
\hline & Obesity III $^{6}$ & 14 & 2.1 & 2 & 0.4 & 16 & 1.3 \\
\hline \multicolumn{8}{|c|}{ Central Obesity (excluding Pregnancy) } \\
\hline & No & 166 & 25 & 339 & 59.8 & 505 & 41.1 \\
\hline & Yes & 497 & 75 & 228 & 40.2 & 725 & 58.9 \\
\hline \multicolumn{8}{|c|}{ Blood Pressure (including under treatment) } \\
\hline & Hypotensive $^{7}$ & 275 & 41.4 & 242 & 42.7 & 517 & 42 \\
\hline & Normotensive $^{8}$ & 150 & 22.6 & 184 & 32.5 & 334 & 27.1 \\
\hline & Hypertensive $^{9}$ & 239 & 36 & 141 & 24.9 & 380 & 30.9 \\
\hline \multicolumn{8}{|c|}{ Blood Sugar elevated $^{10}$ ( Diabetes Mellitus including under treatment) } \\
\hline & No & 610 & 91.9 & 508 & 89.6 & 1118 & 90.8 \\
\hline & Yes & 54 & 8.1 & 59 & 10.4 & 113 & 9.2 \\
\hline \multicolumn{8}{|c|}{ Total Cholesterol } \\
\hline & $<190 \mathrm{mg} / \mathrm{dL}$ & 440 & 66.3 & 382 & 67.4 & 822 & 66.8 \\
\hline & $\geq 190 \mathrm{mg} / \mathrm{dL}$ & 224 & 33.7 & 185 & 32.6 & 409 & 33.2 \\
\hline \multicolumn{8}{|l|}{ LDL } \\
\hline & $<100 \mathrm{mg} / \mathrm{dL}$ & 313 & 47.1 & 241 & 42.5 & 554 & 45 \\
\hline & $\geq 100 \mathrm{mg} / \mathrm{dL}$ & 351 & 52.9 & 326 & 57.5 & 677 & 55 \\
\hline \multicolumn{8}{|c|}{ HDL( borderline $40 \mathrm{mg} / \mathrm{dL}$ for male and $50 \mathrm{mg} / \mathrm{dL}$ for female) } \\
\hline & $\geq 40$ or $50 \mathrm{mg} / \mathrm{dL}$ & 185 & 27.9 & 269 & 47.4 & 454 & 36.9 \\
\hline & $<40$ or $50 \mathrm{mg} / \mathrm{dL}$ & 479 & 72.1 & 298 & 52.6 & 777 & 63.1 \\
\hline \multicolumn{8}{|c|}{ Triglycerides $($ missing $=25)$} \\
\hline & $<150 \mathrm{mg} / \mathrm{dL}$ & 526 & 79.2 & 454 & 80.1 & 980 & 79.6 \\
\hline & $\geq 150 \mathrm{mg} / \mathrm{dL}$ & 138 & 20.8 & 113 & 19.9 & 251 & 20.4 \\
\hline \multicolumn{8}{|c|}{$\begin{array}{l}{ }^{1} \text { BMI }<18.5,{ }^{2} \text { BMI 18.5-24.9, }{ }^{3} \text { BMI 25-29.9, }{ }^{4} \text { BMI } 30-35,{ }^{5} \text { BMI } 35-40,{ }^{6} \text { BMI }>40,{ }^{7} \\
\text { Systolic Blood Pressure (SBP) } 120 \mathrm{mmHg} \text { and Diastolic Blood Pressure (DBP) } 80 \mathrm{mmHg},{ }^{8} \\
\text { SBP 120-140mmHg and DBP } 80-90 \mathrm{mmHg},{ }^{9} \mathrm{SBP} \geq 140 \mathrm{mmHg} \text { and DBP } \geq 90 \mathrm{mmHg},{ }^{10} \mathrm{FBS} \geq \\
126 \mathrm{mg} \%\end{array}$} \\
\hline
\end{tabular}

